\title{
A REVIEW ON: THE EFFECT OF COIR FIBRE ON MECHANICAL PROPERTIES IN CONCRETE
}

\author{
Pankaj H. Gahlot \\ Department of Civil Engineering \\ K.D.K. College of Engineering \\ Nagpur, Maharashtra, India
}

\begin{abstract}
In this concrete project, we have to study how the physical properties of coconut fibre should be improved to strengthen the value of concrete properly. The numerical value which belongs to mechanical properties of coir fibre reinforced concrete is much better than plain conventional concrete; this all predict in the present research. The impact loading on concrete specimens must be proper and convinced which shows better results by using a uniform testing machine. The relationship between PF and CFRC was examined and distinguish between both the mechanical properties.
\end{abstract}

Keywords - Coir Fibre, Treatment

\section{INTRODUCTION}

Coir fibre is one of the finest natural fibres which possess good strengthen properties than other natural fibre. Generally, it's obtained in jungle areas where all the plants and roots are followed seasonal variation comes across in environmental procedure. For this project, we required mature coir fibre because it has better physical property than an un-mature coir fibre. There are two types of coir fibre present in nature; mature and un-mature. Both the fibres possess their physical properties but mature fibre follows better properties. Therefore we chose mature coir fibre for this project.

Agricultural waste is a serious environmental problem in various countries. These types of wastes are used in the form of Fibre. There are mainly three types of Fibre available in market steel fibre, synthetic fibre, natural fibre, etc. Natural fibres extracted from the residual peels, leaves, stems, and pulp of plants such as flax, sugarcane, pineapple, banana, coconut, sisal, jute, and oil palm consist primarily cellulose, hemicelluloses, and lignin. Natural fibres offer exceptional mechanical properties, including high toughness and flexibility, which enhance the ductility of relatively brittle cement matrixes. The natural fibre is biodegradable, inexpensive, low density, non-toxic, available worldwide, energy-efficient and eco-friendly.

\author{
Prof. Pallavi S. Randive \\ Department of Civil Engineering \\ K.D.K College of Engineering \\ Nagpur, Maharashtra, India
}

The objective of using coir fibre (Fig.1) is to reinforce the concrete with natural fibre. Mostly in concrete project steel fibre and synthetic fibre are used but the reason for using natural fibre is because it's highly polar due to high polysaccharide content and also its easier availability in nature. The physical properties of coir fibre like

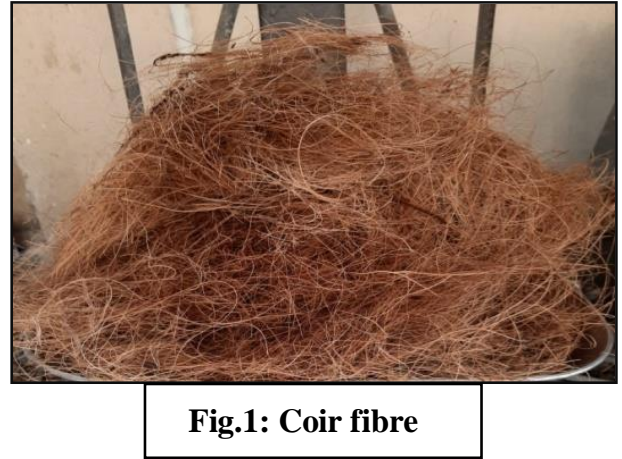

hemicelluloses and cellulose are increasing their characteristic than other natural fibre. Coir fibre, drawn out from the husk of coconuts, is cheap and locally available in various countries. Coconut fibres have the potential to taking strain 4-6 times as compared to other natural fibre.

The following are some characteristics of coir fibre that depend upon its physical and mechanical properties.

1. Aspect Ratio (1/d): Aspect ratio is defined as the ratio of length to the diameter of coir fibre. This is an important parameter to determine the performance of coir fibre in any experiment. If the aspect ratio of coir fibre is correct then results are always on the positive side. Majid Ali et.al.(2012) studied that if the aspect ratio of coir fibre i.e. fibre length of $5 \mathrm{~cm}$ with a fibre content of 5\% by weight of component has better mechanical properties. After examined various aspect ratios, Majid Ali et.al. (2013) that a 3/2 aspect ratio will increase the properties of a component. 


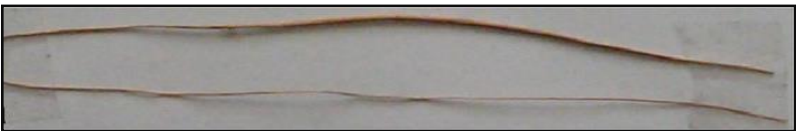

Fig.2: Fibre with changeable diameter along its length

2. Temperature(T): The mechanical properties like young's modulus (E), ultimate tensile strength (UTS), etc. shall be calculated by the effect of processing temperature and measured duration of heating on coir fibre. The term temperature will define the availability of moisture content or water content present in coir fibre. Nagesa Ezekiel et.al. (2011) investigating the effect of temperature and duration of heating on coir fibre; they concluded that after removing of all the moisture content in coir fibre with the help of heating processes. It may follow better mechanical properties than plain mature coir fibre.

3. Seasonal behaviour: The behaviour of coir fibre concerning various seasons such as winter, summer and rainy shall be determined experimentally. Existing literature has reported several merits and demerits on the seasonal behaviour of coir fibre. Md. Nazrul Islam et.al.(2013) studied strength and durability of coconut fibre reinforced concrete in aggressive environments: they conclude that the durability properties of coir fibre in three types of the aggressive environment shall be increased with increase in the proportion of coir fibre.

Coir fibre reinforced concrete has shown to have many useful attributes such as increased compressive strength and tensile strength, post cracking resistance, better energy absorbing characteristics and fatigue strength which plain conventional concrete. Due to impurities and moisture content, coir fibre should pre-treated with several chemicals method for more effective performance. There is some chemical treatment for enhancing the strengthening properties of coir fibre such as Alkali treatment, acetylation, stearic acid treatment, benzylation, peroxide treatment, anhydride treatment, Permanganate treatment, silane treatment, plasma treatment, etc.

\section{REASEARCH FINDING}

All the treatments were used to improvisation of physical as well as mechanical properties of coir fibre. Therefore detailed studies will be investigated based on various literature papers.

1. Alkali Treatment: The treatment of natural fibre by Sodium Hydroxide (NaOH) (Fig.2) is commonly used for composites. The alkali treatment removes the waxy substances on the fibre surface thereby improving the close contact of the fibre-matrix. Huang gu (2009) was studied, the tensile behaviours of coir fibre and related composites after alkali treatment. He told that among all the methods alkali treatment may be considered to be economical processes for increasing adhesive properties of coir fibre. for a detailed study on alkali treatment more, literature papers were studied like Libo yan et.al. (2016) investigated the effect of alkali treatment on coir fibre for reinforced cementitious composites. They concluded that the effect of coir fibre treatment with 5 wt.\% $\mathrm{NaOH}$ solution at $20 \mathrm{c}$ for $30 \mathrm{~min}$ shows better mechanical properties than plain hardening concrete.

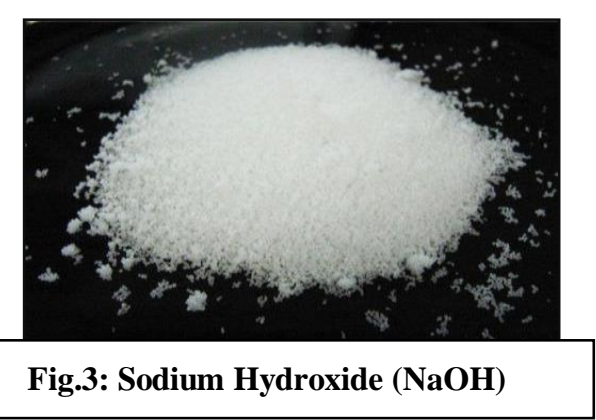

2. Silane Treatment: The Coupling agents usually improve the degree of cross-linking at the interface. Silane coupling agents are effective in modifying the natural fibre-matrix interface. Silanols form in the presence of moisture and hydrolyzable alkoxy groups and react with the cellulose hydroxyl group of the fibre, improving fibre-matrix adhesion and stabilizing the composite properties. F.z.arrakhiz et.al. (2012) examined the impact of chemical treatment on mechanical properties of high-density polyethylene reinforced with chemically modified coir fibre, the result has shown that composites carry better mechanical properties with treated fibre by silane treatment as compared to untreated coir fibre.

3. Benzylation Treatment: In benzylation treatment, Benzyl chloride is used to decrease the hydrophobicity of the fibre and to improve fibre-matrix adhesion leading to an increase in the strength of the composites. Tara sen et.al. (2016) investigated degradability and damaging study of pre-treated natural fibre reinforced polymer by using benzylation treatment. Fibres were immersed in a $10 \% \mathrm{NaOH}$ solution flustered with benzyl chloride. After the process results show intermediate mechanical properties of composites reinforced with pre-treated coir fibre.

Alkali treatment is the most common treatment which is used to reduced impurities in coir fibre proposed by (Huang $\mathrm{Gu}$ (2009); Libo Yan et.al. (2016)). Apart from this, most of the chemicals were also be immerged for better performance of fibre such as Samia Sultan Mir et.al. (2013); Md. Nazrul Islam et.al. has been reported the pre-treatment on fibre using chemical composition of $\mathrm{CrSO} 4+\mathrm{NaHCO} 3$ ( 5 h treated 
by this composition provides best mechanical properties ), S.N.Monteiro et.al. (2008) studied used of pre-treated coir fibre by applying another chemical bonding i.e. methylethyl-ketone, for better durability of fibre Romildo D. Toledo Filho et.al.(2000) reported the use of chemicals like Calcium hydroxide + sodium hydroxide( the original strength of composites shall be increases ), mercerization and bleaching treatment( after modification on coir fibre using this treatment shows improvement in properties), $\mathrm{Fe}(\mathrm{OH}) 3+\mathrm{Al}(\mathrm{OH}) 3$ (both the chemicals increased strength of coir fibre), etc. Most of the chemicals are economically cheap but there have some chemicals which are at a high cost. In all of the studies, chemical treatments on mature coir fibre show massive mechanical properties. Treatment of coir is also dependent upon the proportion and percentage of chemicals as suggested by the researcher.

This study aimed to identify the improvement of mechanical properties in composites concrete where coir fibre was taken as an additive. The advantages being observed about coir fibres are low in cost, low density, reasonable specific strength, good thermal insulation, reduced wear and ability to be recycled with minimum impact on environmental processes. In this investigation, coconut fibre was used as the reinforcement instead of other fibres and for improvisation of mechanical properties in coir fibre, such chemical treatment shall be applied at proper proportion.

\section{CONCLUSION}

As seen in the literature journal, other researchers have done a lot of previous studies to improve the mechanical properties of conventional concrete as a reinforcing agent using coir fiber. Previous researchers have studied a variety of pre-treatments to strengthen coir fiber. Even though various fundamental information has been studied, this helps to makes such type of project. The right selection of procedure and testing is important in order to achieve the objectives of the study.

\section{ACKNOWLEGMENT}

I would like to thanks my guide Prof. Pallavi S. Randive, whose helps me to chosen this project and also provide lots of information about topic. Lastly I wish to thanks $\mathrm{Mr}$. Pandhripande Sir, for provides me knowledge about various chemical treatments on coir fibre.

\section{REFERENCE}

[1] Wang W., Chouw N., Jan. 2017, "The behaviour of coconut fibre reinforced concrete (CFRC) under impact loading", Construction and Building Materials, Vol. 134, Elsevier scientific publication, pp452-461.

[2] Chao-Lung Hwang, Vu-An Tran, and et.al., Sep. 2016 , "Effects of short coconut fiber on the mechanical properties, plastic cracking behavior, and impact resistance of cementitious composites", Construction and Building Materials, Vol.127, Elsevier scientific publication, pp984-992.

[3] Anggraini V., S.M.ASCE, Asadi A, et.al.., April 2016, "Reinforcement Benefits of Nanomodified Coir Fiber in Lime-Treated Marine Clay", Journal Material Civil Engineering 06016005-1, ASCE, pp1943-5533.

[4] Yan L, Chouw N, Huang L, Kasal B, Feb. 2016, "Effect of alkali treatment on microstructure and mechanical properties of coir fibres, coir fibre reinforced-polymer composites and reinforced-cementitious composites", Construction and Building Materials, Vol.112, Elsevier scientific publication, pp168-182.

[5] Yan L, Shen Su, Chouw N, June 2015, "Microstructure, flexural properties and durability of coir fibre reinforced concrete beams externally strengthened with flax FRP composites", Composites Part B, Vol.80, Elsevier scientific publication, pp343-354.

[6] Ozge Andic-Cakir, Sarikanat M, et.al., Jan. 2014, "Physical and mechanical properties of randomly oriented coir fiber-cementitious composites",Composite:Part B, Vol.61, Elsevier scientific publication, pp 49-54.

[7] Ali M, Xiaoyang Li, Chouw N, Aug. 2013, "Experimental investigations on bond strength between coconut fibre and concrete", Materials and Design, Vol.44, Elsevier scientific publication, pp596-605

[8] Samia Sultana Mi, Nafsi N, et.al., May 2013, "Improvement of physico- mechanical properties of coirpolypropylene biocomposites by fiber chemical treatment", Materials and Design, Vol.52, Elsevier scientific journal, pp251-257.

[9] Arrakhiz F, M.El Achaby, et.al., Jan. 2012, "Mechanical properties of high density polyethylene reinforced with chemically modified coir fibres: Impact of chemical treatments", Material and Design, Vol. 37, Elsevier scientific publication, pp379- 383.

[10] Ali M, Liu A, Hou Sou, ChonwJan. 2012, "Mechanical and dynamic properties of coconut fibre reinforced concrete",Construction and Building Materials, Vol.30, Elsevier scientific publication, pp814-825.

[11] S. Harish, D. Peter Michael, et.al., July 2009, "Mechanical property evaluation of natural fiber coir composite", Material Characterization, Vol. 60, Elsevier scientific publication, pp44-49.

[12] Asasutjarit C, Charoenvai S, Hirunlabh J, Joseph Khedari, April 2009,"Materials and mechanical properties of pretreated coir-based green composites", Composites: Part B, Vol. 40, Elsevier scientific publication, pp633637.

[13] Huang Gu, Jan. 2009,“Tensile behaviours of the coir fibre and related composites after $\mathrm{NaOH}$ treatment", Materials and Design, Vol.30, Elsevier scientific publication, pp3931-3934. 
Published Online May 2020 in IJEAST (http://www.ijeast.com)

[14] V.M.John, M.A.Cincotto,, et.al, Jan.2005, "Durability of slag mortar reinforced with coconut fibre", Cement \& Concrete Composites, Vol.27, Elsevier scientific publication, pp565-574. 